\title{
Immediaat geplaatste fronttandimplantaten 2 . Objectief en subjectief esthetisch behandelresultaat
}

In dit onderzoek werd het esthetische behandelresultaat geanalyseerd van immediate implantaatplaatsing bij 16 patiënten. Tijdens de implantaatplaatsing werd de ruimte tussen het implantaat en de buccale botlamel opgevuld met een botsubstituut. In het onderzoek werd uitsluitend vervanging van enkelvoudige gebitselementen geïncludeerd; de uiteindelijke kronen werden 3 tot 6 maanden na implantaatplaatsing bevestigd, alle met een individueel vervaardigde implantaatopbouw met een 'emerging profile' en implantaatplatform. De postoperatieve esthetiek werd geanalyseerd aan de hand van klinische foto's en patiënttevredenheidsenquêtes. De objectief behaalde White Esthetic Score en Pink Esthetic Score, met een gemiddelde waarde van respectievelijk 8,4 en 11,8 , bereikten een hoge score, hetgeen eveneens gold voor de patiënttevredenheid inzake de behandeling en het behandelresultaat (met een gemiddelde van 8 ,7). Geconcludeerd kan worden dat immediate implantaatplaatsing, waarbij de buccale ruimte wordt opgevuld met een botsubstituut, in combinatie met een uiteindelijke kroon met een 'emerging profile', leidt tot een objectief en subjectief goed esthetisch eindresultaat en een hoge mate van patiënttevredenheid.

Graauwmans FEJ, Staas TA, Groenendijk E, Meijer GJ. Immediaat geplaatste fronttandimplantaten 2. Objectief en subjectief esthetisch behandelresultaat Ned Tijdschr Tandheelkd 2015; 122: 193-198

doi: $10.5177 /$ ntvt.2015.04.14182

\section{Inleiding}

Wanneer een maxillair frontelement restauratief en/of endodontisch uitbehandeld is, kan extractie en het in dezelfde sessie plaatsen van een implantaat een goede behandeloptie zijn. Hierdoor wordt getracht de natuurlijke collaps van harde en zachte weefsels te voorkomen (Quirynen et al, 2007). Volgens het conventionele implantologieprotocol wordt na extractie eerst de wondgenezing afgewacht en, zo nodig, eerst het bottekort aangevuld alvorens tot implantaatplaatsing over te gaan. Hierbij vormt iedere behandelstap een risico met bijkomende complicaties. Daarentegen kan bij immediate implantaatplaatsing het complex van weke delen zijn oorspronkelijke contour behouden, mits het betrokken gebitselement atraumatisch, dat wil zeggen zonder kwetsuur van weke delen, wordt verwijderd (Schwartz-Arad en Chaushu, 1997). De basis voor immediate implantaatplaatsing met daarop het in dezelfde sessie aanbrengen van een tijdelijke voorziening komt voort uit de gedachte dat een continue ondersteuning van de weke delen met behoud van mucosale integriteit leidt tot een voorspelbaar esthetisch resultaat (Atieh et al, 2009).

De patiënt ziet het behaalde esthetisch eindresultaat als belangrijkste parameter voor het succes van de implantaat-

\author{
Leerdoelen \\ $\mathrm{Na}$ het lezen van dit artikel weet $\mathrm{u}$ : \\ - wat de patiënttevredenheid en het subjectief esthetische \\ behandelresultaat zijn van het immediaat plaatsen van \\ solitaire fronttandimplantaten met opvulling van de \\ buccale ruimte.
}

behandeling (Ferrus et al, 2010). Om op een objectieve manier de esthetiek te scoren werden objectieve indices in de vorm van de White Esthetic Score (WES) en de Pink Esthetic Score (PES) geïntroduceerd (Fürhauser et al, 2005; Belser et al, 2009). De subjectieve beoordeling van de patiënt zelf kan via een enquête worden geïnventariseerd. In het huidige onderzoek werd het esthetisch resultaat geanalyseerd van patiënten met een immediaat geplaatst implantaat conform een eenduidig behandelprotocol. Eerder werd in een artikel beschreven dat, na plaatsen van een implantaat (NobelActive ${ }^{\mathrm{TM}}$ Internal) in combinatie met een aangebracht botsubstituut (Bio-Oss ${ }^{\circledR}$ ), direct-postoperatief de botlameldikte gemiddeld van $0,9 \mathrm{~mm}$ tot $2,4 \mathrm{~mm}$ toenam, waarna gemiddeld na 43 tot 202 weken met een gemiddelde van 103 weken (sd 44) een kleine afname optrad $(-0,6 \mathrm{~mm})$ tot $1,8 \mathrm{~mm}$. De botlamel nam in hoogte met gemiddeld 1,6 $\mathrm{mm}$ toe, tot gemiddeld 1,2 $\mathrm{mm}$ boven het niveau van de implantaatschouder (Graauwmans et al, 2015). In dit artikel worden de resultaten van de behaalde esthetiek en patiënttevredenheid gepresenteerd.

\section{Wat weten we?}

Conventionele vervanging van een maxillair frontelement door een implantaatgedragen kroon vergt vaak een voorafgaande botopbouw, waardoor de behandelduur wordt verlengd.

\section{Wat is nieuw?}

Immediate plaatsing ter vervanging van een solitair maxillair frontelement, waarbij de buccale ruimte wordt opgevuld met een botsubstituut, levert een hoog esthetisch eindresultaat en een hoge patiënttevredenheid op.

\section{Praktijktoepassing}

Voor een goed esthetisch resultaat en een hoge patiënttevredenheid is het zinvol om tijdens een behandeling met immediate implantaatplaatsing de ruimte tussen de buccale botlamel en het implantaat op te vullen met een botsubstituut. 


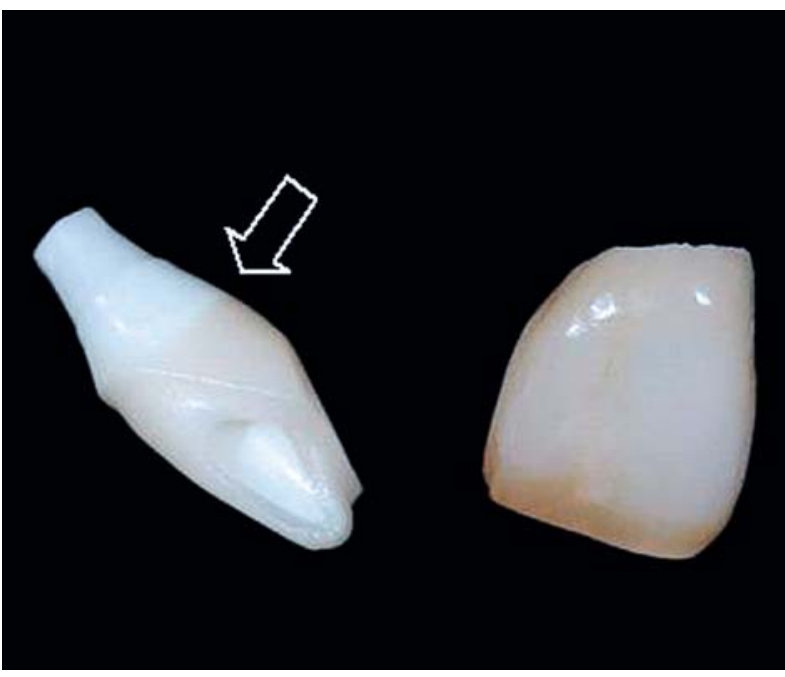

Afb. 1. Emerging profile in vormgeving van de definitieve opbouw, rechts de te cementeren definitieve kroon.

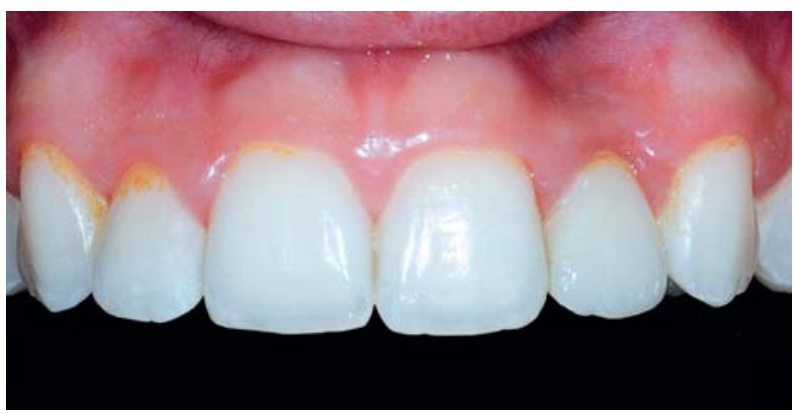

Afb. 3. Frontaal genomen lichtopname van een casus met een maximale WES-score van 10 en een PES-score van 14. Het implantaat is gesitueerd ter plaatse van gebitselement 12

\section{Materiaal en methode}

In een verwijspraktijk voor implantologie in 's-Hertogenbosch werden de statussen beoordeeld van alle patiënten bij wie in de periode van 1 januari 2008 tot 1 januari 2012 in het maxillaire front immediaat geïmplanteerd werd. $\mathrm{Na}$ de immediate implantaatplaatsing werd aansluitend een tijdelijke brug aangebracht, waarbij in het geval van een afdekschroef of genezingsopbouw een directe glasvezelcomposiet brug werd vervaardigd en na plaatsing van een immediate tijdelijke implantaatopbouw een tijdelijke composietkroon. Na een genezingsfase (variërend van 3 tot 6 maanden), waarin tussentijds de tijdelijke constructie kon worden afgenomen teneinde de buccale gingiva en interdentale papillen te recontoureren om daarmee het ideale 'emerging profile' te creëren, werd de definitieve afdruk gemaakt. Aan de hand hiervan werd een individuele opbouw met individueel gevormd emerging profile vervaardigd (afb. 1), die bij voorkeur werd verschroefd en waarop vervolgens de definitieve keramiekkroon werd geplaatst.

Van alle geïncludeerde patiënten werden tijdens de reguliere controle lichtopnamen gemaakt van het maxillaire front. Hiervoor werd een spiegelreflexcamera gebruikt met macroflitser. Standaard werd een Spandex ${ }^{\circledR}$-retractor met een intraorale zwarte contrastor toegepast conform de handleiding voor digitale mondfotografie (Van Oort, 2009).

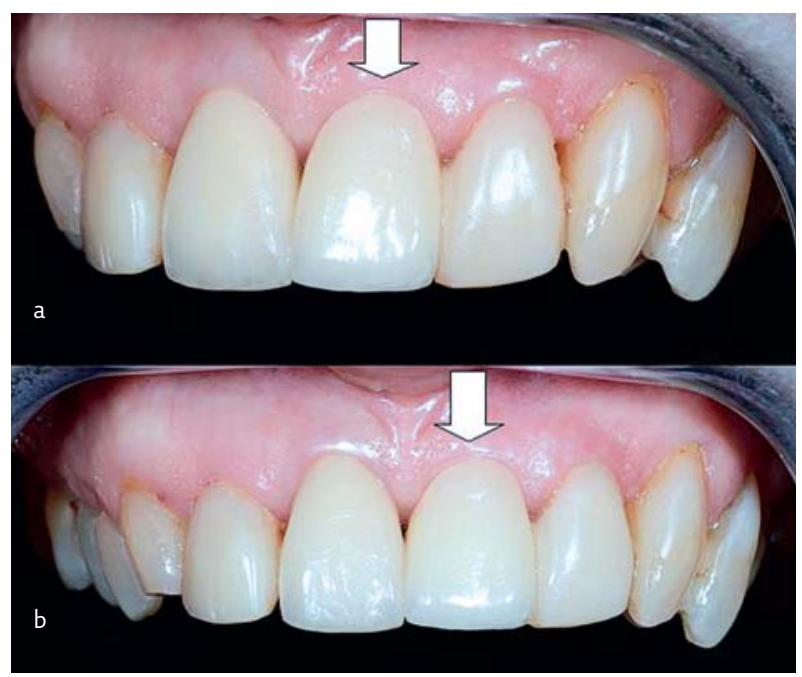

Afb. 2. Lichtopname frontaal gecentreerd op de mediaanlijn en gecentreerd op het mid-buccale vlak van de kroon (implantaat: regio 21).

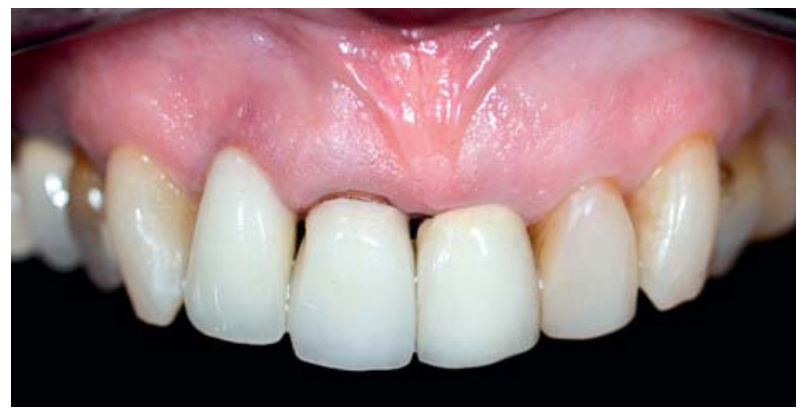

Afb. 4. Frontaal genomen lichtopname van een casus met een PES-score van 7 en een WES-score van 3. Het implantaat is gesitueerd ter plaatse van gebitselement 12 .

Van iedere patiënt werden 2 lichtopnamen gemaakt: 1 frontaal gecentreerd op de mediaanlijn en 1 gecentreerd op het mid-buccale vlak van de kroon (afb. 2). Aan de hand van deze lichtopnamen werden door 1 onafhankelijk beoordelaar de esthetische aspecten van zowel de kroon als van de peri-implantaire weefsels gescoord. Voor de interbeoordelaarsbetrouwbaarheid werd een tweede onafhankelijke beoordelaar ingezet.

De White Esthetic Score (WES) beoordeelt de esthetiek van de restauratie op 5 punten; vorm en outline, alsmede de kleur, textuur en translucentie van de kroon (Belser et al, 2009). De score loopt van 0 tot en met 2, waarbij 2 de hoogste waardering weergeeft; in totaal kan een maximum van 10 punten worden gehaald. Voor beoordeling wordt het contralaterale gebitselement als referentie genomen (afb. 3 en 4).

De Pink Esthetic Score (PES) evalueert de esthetiek van de peri-implantaire weke delen op 7 punten; hoogte van mesiale en distale papil, contour van de weke delen, niveau van mucosa ter plaatse van het midden van de kroon, contour van processus alveolaris aan de buccale zijde en de kleur/ textuur van de buccale mucosa (Fürhauser et al, 2005). De score loopt van 0 tot en met 2, waarbij 2 geldt als hoogste waardering, waardoor in totaal een maximum van 14 punten kan worden gehaald. De weke delen worden gescoord met 
Hoe hebt u de tijdsduur van de behandeling bij het immediaat implanteren ervaren?

Hoe ervoer u de nabezwaren (zoals zwelling en/of napijn) in de eerste 2 weken na plaatsing van het implantaat?

Zou u dezelfde behandeling nogmaals willen ondergaan in een vergelijkbare situatie?

Zou u anderen desgevraagd de behandeling van het immediaat implanteren aanraden?

\section{Resultaat}

Wat vindt u van de kleur van het tandvlees rond het implantaat?

Hoe beoordeelt $\mathrm{u}$ de vorm en plaats van de rand van het tandvlees rond het implantaat?

Als $\mathrm{u}$ het tandvlees rondom het implantaat vergelijkt met de andere voortanden, oogt het tandvlees naar uw mening natuurlijk?

Hoe beoordeelt u de vorm en kleur van de kroon op het implantaat?

\section{Totaal beoordeling}

Wat is uw algehele waardering/ervaring/beoordeling van de ondergane behandeling in combinatie met het resultaat?
Registratienummer

\begin{tabular}{|c|c|c|c|c|c|c|}
\hline kort & 1 & 2 & 3 & 4 & 5 & lang \\
\hline beperkt & 1 & 2 & 3 & 4 & 5 & heftig \\
\hline zeker niet & 1 & 2 & 3 & 4 & 5 & zeker wel \\
\hline zeker niet & 1 & 2 & 3 & 4 & 5 & zeker wel \\
\hline
\end{tabular}

\begin{tabular}{|c|c|c|c|c|c|c|}
\hline niet mooi & 1 & 2 & 3 & 4 & 5 & mooi \\
\hline niet mooi & 1 & 2 & 3 & 4 & 5 & mooi \\
\hline zeker niet & 1 & 2 & 3 & 4 & 5 & zeker wel \\
\hline niet mooi & 1 & 2 & 3 & 4 & 5 & mooi \\
\hline
\end{tabular}

Eventuele opmerkingen

Afb. 5. Enquêteformulier ter evaluatie van de patiënttevredenheid na immediaat geplaatste implantaat.

als referentie de peri-implantaire weke delen van het gebitselement aan de contralaterale zijde (afb. 3 en 4).

Teneinde de indruk, de mening en de ervaring van de patiënt omtrent de behandeling en het resultaat te inventariseren werd een geanonimiseerde vragenlijst afgenomen. Deze bestond uit 8 korte vragen en 1 totaalscore in de vorm van een rapportcijfer (afb. 5). De vragenlijst was specifiek voor de evaluatie van de immediaat geplaatste implantaten opgesteld en conform adviezen en richtlijnen voor het opstellen van patiëntenquêtes (Vermylen et al, 2003; CBO, 2007).

Van de WES-index werd de intrabeoordelaarsbetrouwbaarheid bepaald door alle casussen een tweede maal te scoren op subscores en totaalscore. Zodoende kon voor de losse subscores een toetsing met een Cohen's kappa worden verricht. Met betrekking tot de totaalscore werden t-testen toegepast. Daarbij geldt de volgende interpretatie van de Cohen's kappa: 'slecht' $(\kappa<0)$; 'gering' $(0-0,20)$; 'matig' (0,21-0,40); 'redelijk' (0,41-0,6); 'goed' (0,61$0,80)$ of 'zeer goed' $(0,81-1,00)$. De interbeoordelaarsbetrouwbaarheid van de WES-index werd op vergelijkbare wijze verricht, zo ook de intra- en interbeoordelaarsbetrouwbaarheid van de PES-index.

Van alle bepalingen werd het gemiddelde en de standaarddeviatie berekend. Een verschil tussen de waargenomen WES-index en PES-index, een verschil tussen de waargenomen WES-index en de totaalscore uit de enquête en een verschil tussen de waargenomen PES-index en de totaalbeoordeling uit de enquête werden geanalyseerd met behulp van kruistabellen en de chikwadraattoets. Hiervoor werden de scores van de WES verdeeld in scoregroepen 0-8 en 9-10, de scores van de PES-index in scoregroepen 0-12 en 13-14 (conform de verdeling bij de intra- en interbeoordelaarstoetsing) en de totaalscore in scoregroepen 0-8 en 9-10.

De subscores in de WES-index en PES-index in relatie tot de enquêtevragen met betrekking tot de esthetische tevredenheid, werden met een variant van de chikwadraattoets (de Fisher's Exact Test) getoetst op onderlinge verschillen tussen 1 . WES-subscore 'tandvorm' en de achtste enquêtevraag 'kroon', 2. WES-subscore 'kleur' en de achtste enquêtevraag 'kroon', 3. PES-subscore 'kleur weke delen' en de vijfde enquêtevraag 'kleur', 4. PES-subscore 'niveau weke delen' en de zesde enquêtevraag 'vorm + rand', 5. PES-subscore 'contour weke delen' en de zesde enquêtevraag 'vorm + rand', en 6. PES-totaalscore en de zevende enquêtevraag 'natuurlijk'.

Daarbij werden de subscores van PES en WES ingedeeld in scoregroepen 0,1 en 2 . De enquêtevraagscores werden ingedeeld in scoregroepen 1-2, 3 en 4-5. Bij de vergelijking tussen de PES-totaalscore en de zevende enquêtevraag 'natuurlijk' werden de scoregroepen van de PES-totaalscore in scoregroepen 1-12 en 13-14 verdeeld.

Een verschil tussen de leeftijd van de patiënt en de totaalbeoordeling in de enquête werd met een chikwadraattoets met bijkomende $\mathrm{p}$-waarden en eerder omschreven interpretatie geanalyseerd door de leeftijd in te delen in groepen $0-50$ en 50-100 en de totaalbeoordeling in scoregroepen 0-8 en 9-10.

\section{Resultaten}

De geïncludeerde patiënten varieerden in leeftijd van 17 tot 72 jaar (gemiddeld 44), onder wie 4 mannen en 12 vrouwen. De evaluatie vond plaats 60 tot 202 weken (gemiddeld 107) na implantaatplaatsing. 


\begin{tabular}{|lllll|} 
& Maximum & Minimum & sd & Gemiddeld \\
\hline Tandvorm & 2 & 0 & 0,619 & 1,375 \\
Tand outline & 2 & 0 & 0,632 & 1,500 \\
Kleur & 2 & 0 & 0,619 & 1,625 \\
Textuur oppervlakte & 2 & 2 & 0,0 & 2,0 \\
Translucentie & 2 & 1 & 0,342 & 1,875 \\
Totaalscore WES & 10 & 3 & 1,668 & 8,375 \\
\hline
\end{tabular}

Tabel 1. Overzicht van gemiddelde en standaarddeviatie (sd) bij bepalingen van de WES-index met $n=16$. De eerste kolom en tweede kolom geven respectievelijk de maximaal en minimaal behaalde subscore per item aan.

\begin{tabular}{|lllll|} 
& Maximum & Minimum & sd & Gemiddeld \\
\hline Mesiale papil & 2 & 1 & 0,3416 & 1,875 \\
Distale papil & 2 & 1 & 0,5123 & 1,563 \\
Contour weke delen & 2 & 0 & 0,6021 & 1,688 \\
Niveau weke delen & 2 & 1 & 0,4031 & 1,813 \\
Contour processus alveolaris & 2 & 0 & 0,6292 & 1,563 \\
Kleur weke delen & 2 & 0 & 0,6292 & 1,438 \\
Textuur weke delen & 2 & 0 & 0,5774 & 1,750 \\
Totaalscore PES & 14 & 7 & 1,7212 & 11,813 \\
\hline
\end{tabular}

Tabel 2. Overzicht van gemiddelde en standaarddeviatie (sd) bij bepalingen van de PES-index met $\mathrm{n}=16$. De eerste kolom en tweede kolom geven respectievelijk de maximaal en minimaal behaalde subscore per item aan.

Peroperatief werd bij 1 patiënt een genezingsopbouw geplaatst, bij 6 patiënten een immediate tijdelijke implantaatopbouw en bij 9 patiënten een afdekschroef. Alle definitieve kronen werden geplaatst op individueel vervaardigde implantaatopbouwen met een emerging profile, waarbij gebruikgemaakt werd van 'platform switching', een concept waarbij smallere prothetische componenten op een breder implantaatplatform worden geplaatst.

De WES-scores staan vermeld in tabel 1, de PES-scores in tabel 2 en de enquête-uitkomsten in tabel 3.

De reproduceerbaarheid van herhaling door dezelfde beoordelaar van de WES-index bleek goed (tab. 4). Met betrekking tot de totaalscore van de WES-index bleek de correlatie hoog $(0,859)$ en bleek de structurele meetfout $(0,250)$ bij toetsing niet-significant $(p=0,261)$.

De reproduceerbaarheid van herhaling door een tweede beoordelaar van de WES-index bleek matig (tab. 4). Toch bleek met betrekking tot de totaalscore van de WES-index de correlatie hoog $(0,865)$ en was de structurele meetfout $(-0,375)$ bij toetsing niet significant $(p=0,111)$.

In de herhaling door dezelfde beoordelaar van de PESindex (tab.5) bleek structureel een meetfout aanwezig waarbij het tweede meetmoment een half indexpunt lager werd gescoord. Met betrekking tot de totaalscore van de PES-index bleek de correlatie hoog $(0,940)$, maar was de structurele meetfout $(0,563)$ bij toetsing significant $(p=0,007)$. De maximale omvang van de structurele meetfout $(0,950$ punt) betekent dat bijna een heel punt verschil kan optreden.

In de herhaling door een tweede beoordelaar van de PES-index bleek structureel een meetfout aanwezig, waar- bij door de tweede beoordelaar zo'n 0,8 indexpunt hoger werd gescoord. Met betrekking tot de totaalscore van de PES-index bleek de correlatie hoog $(0,852)$. De structurele meetfout $(-1,063)$ bleek bij toetsing significant $(p=0,002)$.

De WES- en PES-index gaven bij toetsing onderling een Fisher's Exact Testwaarde van 1,000, de PES-index versus de totaalscore in de enquête een Fisher's Exact Testwaarde van 0,302 en de WES-index ten opzichte van de totaalscore in de enquête een Fisher's Exact Testwaarde van 0,358 . De subscore 'tandvorm' in de WES-index gaf vergeleken met de achtste enquêtevraag 'kroon' een nietsignificante Fisher's Exact Testwaarde ( $\mathrm{p}=0,500$ ), de WES-subscore 'kleur' en de achtste enquêtevraag 'kroon' een $\mathrm{p}=0,312$, de PES-subscore 'kleur weke delen' en de vijfde enquêtevraag 'kleur' een $\mathrm{p}=1,000$, de PES-subscore 'niveau van weke delen' en de zesde enquêtevraag 'vorm + rand' een $\mathrm{p}=0,245$, de PES-subscore 'contour weke delen' en de zesde enquêtevraag 'vorm + rand' een $\mathrm{p}=0,136$ en de PES-totaalscore versus de zevende enquêtevraag 'natuurlijk' een $\mathrm{p}=0,250$.

Leeftijd en totaalbeoordeling in de enquête bleken geen significante relatie te hebben $(\mathrm{p}>0,05)$.

\section{Discussie}

Dat bij de WES- en PES-index velerlei kappa-waarden gevonden werden voor de afzonderlijke subscores en totaalscores hangt samen met het karakter van beide indices: het zijn cumulatieve indices die bestaan uit een beperkt aantal subscores met slechts 3 categorieën: 0,1 of 2 . Hoe kleiner het aantal scoremogelijkheden, hoe makkelijker een kleine afwijking statistische relevantie krijgt. De uitkomst van de 


\begin{tabular}{|lllll|}
\hline & Maximum & Minimum & sd & Gemiddeld \\
Tijdsduur & 5 & 1 & 1,2111 & 2,000 \\
Nabezwaren & 5 & 1 & 1,2894 & 1,938 \\
Nogmaals ondergaan & 5 & 3 & 0,7188 & 4,625 \\
Aanraden & 5 & 3 & 0,8165 & 4,500 \\
Kleur gingiva & 5 & 3 & 0,7188 & 4,375 \\
Vorm + rand & 5 & 3 & 0,8732 & 4,313 \\
Vergelijk & 5 & 2 & 0,9639 & 4,438 \\
Kroon & 5 & 2 & 0,8139 & 4,563 \\
Totaalscore & 10 & 7 & 0,8509 & 8,656 \\
\hline
\end{tabular}

Tabel 3. Overzicht van gemiddelde en standaarddeviatie (sd) bij de enquêtescores met $n=16$. De eerste kolom en tweede kolom geven respectievelijk de maximaal en minimaal behaalde subscore per item aan.

\begin{tabular}{|lll|}
\hline WES-score & Intrabeoordelaar (kappa) & Interbeoordelaar (kappa) \\
\hline Tandvorm & 0,775 (goed) & 0,217 (matig) \\
Tand outline & 0,768 (goed) & 0,238 (matig) \\
Kleur & 0,628 (goed) & 0,407 (redelijk) \\
Translucentie & 1,000 (zeer goed) & 0,429 (redelijk) \\
Textuur & 0,000 (gering) & 0,000 (gering) \\
\hline
\end{tabular}

Tabel 4. WES-index: intra- en interbeoordelaarsbetrouwbaarheid (Cohen's kappa)

\begin{tabular}{|lll|}
\hline PES-score & Intrabeoordelaar (kappa) & Interbeoordelaar (kappa) \\
\hline Mesiale papil & 1,000 (zeer goed) & 0,130 (gering) \\
Distale papil & 0,875 (zeer goed) & 0,067 (gering) \\
Contour weke delen & 0,556 (redelijk) & 0,765 (goed) \\
Niveau weke delen & 0,856 (zeer goed) & 0,828 (zeer goed) \\
Contour processus alvolaris & 0,881 (zeer goed) & 0,050 (gering) \\
Kleur weke delen & 0,892 (zeer goed) & 0,138 (gering) \\
Textuur weke delen & 0,692 (goed) & 0,543 (redelijk) \\
\hline
\end{tabular}

Tabel 5. PES-index: intra- en interbeoordelaarsbetrouwbaarheid (Cohen's kappa)

intra- en interbeoordelaarsbetrouwbaarheid in dit onderzoek is zodoende statistisch 'redelijk' en in het licht van slechts 16 casussen relatief goed.

In 2009 werden de eerste 2 artikelen gepubliceerd over de PES-scores van patiënten met enkeltandvervangingen in het bovenfront. In beide onderzoeken werd het effect van het plaatsen van een implantaat binnen 4-8 weken na extractie geëvalueerd. Belser et al (2009) beschreven 45 patiënten en zij vermeldden een gemiddelde PES-score van 7,8. Buser et al (2009) noteerden voor 20 patiënten een PES-score van 8,1 . In een onderzoek, waarin pas na 3 maanden na extractie werd geïmplanteerd, bleek de gemiddelde PES-score van $6,3(n=92)$ fors lager. Dit lage getal werd vooral verklaard door het feit dat de uitgangssituatie bij deze patiëntengroep ongunstiger was, want bij ongeveer een derde van de onderzoekspopulatie werd eerst pre-implantologische chirurgie uitgevoerd, wat in het algemeen het esthetisch eindresultaat negatief beïnvloedt (Den Hartog et al, 2013).

De bepaalde WES- en PES-scores uit dit onderzoek (respectievelijk gemiddeld 8,4 en 11,8) zijn hoger dan in andere onderzoeken naar immediaat implanteren. Zo beschreven Cosyn et al (2011) gemiddelde WES- en PES-scores van respectievelijk 8,2 en 10,5 na 3 jaar. Raes et al (2011) publiceerde WES- en PES-scores van respectievelijk 7,2 en 10,3 na 1 jaar en Noelken et al (2013) vermeldden een PES-score van 11,3 na ruim 2 jaar.

Het immediaat implanteren in dit onderzoek, dus met applicatie van Bio-Oss ${ }^{\circledR}$, en een kroon met emerging profile en platform switching, leidt tot een hogere esthetische uitkomst dan een behandeling met conventionele implantologie (Pieri et al, 2013).

Het gebruik van de WES- en PES-index bij analyse van de 16 casussen werd bij 2 patiënten positief beïnvloed door behandelingen aan de buurelementen. Zo is er $1 \mathrm{ca}^{-}$ sus waarin gelijktijdig een conventionele kroon op het buurelement werd geplaatst. In een andere casus werd aansluitend aan het implanteren een gingivatransplantaat geplaatst om een afdichting van de extractiealveole te bewerkstelligen.

De behaalde patiënttevredenheid (gemiddeld 8,7) werd ook gevonden in een ander onderzoek dat immediate implantaatplaatsing evalueerde en is tevens vergelijkbaar met een behandeling met conventioneel geplaatste implantaten (Levi et al, 2003; Raes et al, 2011). 
Conform de bevindingen in dit onderzoek wees eerder onderzoek al uit dat de PES-index als objectieve meetmethode en een patiëntenondervraging als subjectieve inventarisatie, geen significante relatie vertonen (Eghbali et al, 2012).

\section{Conclusie}

Uit dit onderzoek is gebleken in een eentandsvervanging na immediate implantaatplaatsing met opvulling van de buccale ruimte dat de WES-scores (gemiddeld 8,4 op een schaal van 0-10) en de PES-scores (gemiddeld 11,8 op een schaal 0-14) hoog zijn en dat de patiënttevredenheid over zowel de behandeling als het resultaat hoog is (gemiddeld 8,7 op een schaal van 1-10).

\section{Literatuur}

* Atieh MA, Payne AG, Duncan WJ, Cullinan MP. Immediate restoration/ loading of immediately placed single implants: is it an effective bimodal approach? Clin Oral Implants Res 2009; 20: 645-659.

* Belser UC, Grutter L, Vailati F Bornstein MM, Weber HP, Buser D. Outcome evaluation of early placed maxillary anterior single-tooth implants using objective esthetic criteria: a cross-sectional, retrospective study in 45 patients with a 2- to 4-year follow-up using pink and white esthetic scores. J Periodontol 2009; 80: 140-151.

* Buser D, Halbritter S, Hart C, et al. Early implant placement with simultaneous guided bone regeneration following single-tooth extraction in the esthetic zone: 12-month results of a prospective study with 20 consecutive patients. J Periodontol 2009; 80: 152-162.

* $C B O$. Handleiding patiëntenenquêtes. Aan de slag met schriftelijke of elektronische patiëntenenquêtes binnen uw zorginstelling. Utrecht: Kwaliteitsinstituut voor de Gezondheidszorg CBO, 2007.

* Cosyn J, Eghbali A, De Bruyn H, Collys K, Cleymaet R, De Rouck T. Immediate single-tooth implants in the anterior maxilla: 3-year results of a case series on hard and soft tissue response and aesthetics. J Clin Periodontol 2011; 38: 746-753.

* Eghbali A, De Bruyn H, De Rouck T, Cleymaet R, Wyn I, Cosyn J. Single implant treatment in healing versus healed sites of the anterior maxilla: a clinical and radiographic evaluation. Clin Implant Dent Relat Res 2012; 14: 336-346

* Esposito M, Grusovin MG, Polyzos IP, Felice P, Worthington HV. Timing of implant placement after tooth extraction: immediate, immediatedelayed or delayed implants? A Cochrane systematic review. Eur J Oral Implantol 2010; 3 : 189-205.

* Ferrus J, Cecchinato D, Pjetursson EB, Lang NP, Sanz M, Lindhe J. Factors influencing ridge alterations following immediate implant placement into extraction sockets. Clin Oral Implants Res 2010; 21: 22-29.

* Fürhauser R, Florescu D, Benesch T, Haas R, Mailath G, Watzek G. Evaluation of soft tissue around single-tooth implant crowns: the pink esthetic score. Clin Oral Implants Res 2005; 16: 639-644.

* Graauwmans FEJ, Staas TA, Meijer GJ. Immediaat geplaatste fronttandimplantaten 1 . Analyse met cone beam-computertomografie naar remodellering van de buccale botlamel. Ned Tijdschr Tandheelkd 2015; 122: 156-161.

* Hartog L den, Raghoebar GM, Huddleston Slater JJ, Stellingsma K, Vissink A, Meijer HJA. Single-tooth implants with different neck designs: a randomized clinical trial evaluating the aesthetic outcome. Clin Implant Dent Relat Res 2013; 15: 311-321
* Levi A, Psoter W, Agar J, Reisine ST, Taylor TD. Patient self-reported satisfaction with maxillary anterior dental implant treatment. Int J Oral Maxillofac Implants 2003: 18; 113-120.

* Noelken R, Neffe BA, Kunkel M, Wagner W. Maintenance of marginal bone support and soft tissue esthetics at immediately provisionalized OsseoSpeed implants placed into extraction sites: 2-year results. Clin Oral Implants Res 2013; 25: 214-220.

* Oort D van. Digitale mondfotografie. Een praktische handleiding. Houten: Bohn Stafleu Van Loghum, 2009

* Pieri F, Aldini NN, Marchetti C, Corinaldesi G. Esthetic outcome and tissue stability of maxillary anterior single-tooth implants following reconstruction with mandibular block grafts: a 5-year prospective study. Int J Oral Maxillofac Implants 2013; 28: 270-280.

* Quirynen M, Van Assche N, Botticelli D, Berglundh T. How does the timing of implant placement to extraction affect outcome? Int J Oral Maxillofac Implants 2007; 22 Suppl: 203-223.

* Raes F, Cosyn J, Crommelinck E, Coessens P, De Bruyn H. Immediate and conventional single implant treatment in the anterior maxilla: 1-year results of a case series on hard and soft tissue response and aesthetics. J Clin Periodontol 2011; 38: 385-394.

* Schwartz-Arad D, Chaushu G. The ways and wherefores of immediate placement of implants into fresh extraction sites: a literature review. J Periodontol 1997; 68: 915-923.

* Vermylen K, Collaert B, Lindén U, Björn AL, De Bruyn H. Patient satisfaction and quality of single-tooth restorations. Clin Oral Implants Res 2003; 14: 119-124.

\section{Summary}

Immediate front implant placements 2. Objective and subjective aesthetic treatment results

In this study, the aesthetic outcome of treatment was analysed after immediate implant placement in 16 patients. During implant installation the gap between the implant and the buccal plate was filled with a bone substitute. Only single tooth replacements were included; the final crowns were placed 3-6 months after implant installation, all with individual manufactured abutments with an emerging profile and platform switching. Postoperative aesthetics were analysed based on clinical photographs and satisfaction questionnaires. The objectively attained White Esthetic Score and Pink Esthetic Score with an average value of 8.4 and 11.8 respectively, scored high, as was also observed for patient's satisfaction on both treatment and outcome (an average of 8.7). It may be concluded that flapless immediate implant placement together with the application of a bone substitute into the buccal gap in combination with a final crown with emerging profile results in objective and subjective good aesthetics and high patient satisfaction.

\section{Bron}

F.E.J. Graauwmans ${ }^{1}$, T.A. Staas ${ }^{2}$, E. Groenendijk, G.J. Meijer ${ }^{1,4}$ Uit ${ }^{1}$ de vakgroep Implantologie \& Parodontologie van de afdeling Tandheelkunde van het Radboudumc in Nijmegen, ${ }^{2}$ de Implantologieverwijspraktijk Staas \& Bergmans in 's-Hertogenbosch, ${ }^{3}$ de implantologieverwijspraktijk Implantologie Den Haag en ${ }^{4}$ de afdeling Mond-, Kaak- en Aangezichtschirurgie van het Radboudumc in Nijmegen Datum van acceptatie: 17 november 2014

Adres: prof. dr. G.J. Meijer, Radboudumc, Philips van Leydenlaan 25, 6525 EX Nijmegen Gert.Meijer@radboudumc.nl 